\title{
The antecedents of supply chain performance: Business analytics, business process orientation, and information systems support
}

\author{
Mohammad J Adaileh $^{a}$, Muneer Alrwashdeh ${ }^{b^{*}}$, Hasan Z. Abu AlZeat ${ }^{\mathfrak{c}}$ and Nesrin salim Almatarneh ${ }^{\mathrm{d}}$
}

${ }^{a}$ Department of Business Process Design, Business Economics, University of Salamanca, Spain

${ }^{b}$ Assistant Professor of E-marketing, Faculty of Business, Department of E-marketing, Irbid National University, Irbid, Jordan

${ }^{c}$ Management information system Department, College of Business \& Economics (CBE), Qassim University, Kingdom of Saudi Arabia

${ }^{d}$ Assistant Professor of Business, Faculty of Business, Luminus Technical University College, Jordan

\section{A B S T R A C T}

Article history:

Received October 18, 2021

Received in revised format

October 30, 2021

Accepted December 302021

Available online

December 302021

Keywords:

Supply Chain

Supply Chain Performance

Business Analytics

Saudi Arabia

Information Systems Support

\begin{abstract}
This study investigates the impact of business analytics (BA) on supply chain performance (SCP) in Saudi industrial companies. It also investigates the mediating impact of information systems supporting (ISS) and business process orientation (BPO). A total of 373 respondents working in 38 manufacturing companies in the Kingdom of Saudi Arabia (KSA) were selected. A scale with acceptable validity and reliability indicators was developed to measure the study variables. The results indicated significant indirect impact of the business analytics (planning, supply, make, delivery) on supply chain performance as ISS and BPO mediate this impact. Based on the results, a set of recommendations were proposed, industrial companies in KSA must develop the analytical capabilities for managers by increasing awareness of the benefits achieved from using business analytics approaches. It is a critical precedent for supply chain SC efficiency, and for companies to enhance their analytical capabilities with good ISS and process orientation to utilize in analyzing vast amounts of internal and external data. Directions for future research are also presented in this paper.
\end{abstract}

(C) 2022 Growing Science Ltd. All rights reserved.

\section{Introduction}

Effective supply chain management SCM must maintain a competitive advantage and improve organizational performance (Wei et al., 2017; Sohl et al., 2020). Improving efficiency and effectiveness of SC analysis is one of the important elements in increasing the ability of the SC to achieve a competitive advantage (Trkman et al., 2007; Zhu et al., 2018; Wieland et al., 2017). Several ways in which the SC affects performance, among them the employment of the so-called Business Analytics BA and BPO (Sohl et al., 2020; Rai \& Tang, 2014; Mcdonald \& Eisenhardt, 2020). This study seeks to clarify the impact of BA on SCP, considering ISS and BPO as mediator variables through a questionnaire developed for this purpose. Furthermore, the process of improving supply chain performance is a complex task because it involves many processes such as setting standards and objectives (Wieland et al., 2017; Pati et al., 2018; Salonen \& Jaakkola, 2015), planning and communication (Spieth et al., 2019). It is no longer possible to follow conventional wisdom in making supply chain decisions, use measurement or even adopt best practices due to the rapid development of modern technologies and decision-making approaches (Teece, 2018). The decision-making process depends heavily on data analysis in all business applications (Trkman et al., 2015; Visnjic et al., 2016), the analysis of large amounts of both internal and external data (Wei et al., 2017; Zhu et al., 2018), so it is necessary to employ an approach that allows analysis of that data based on organized structure, this approach is called BA (Trkman et al., 2015; Spieth et al., 2019). BA is increasingly used in supply chain management because it is an ongoing process that requires analytical systems to measure performance (Su et al., 2019; Loon \& Chik, 2019). BA

* Corresponding author

E-mail address: Malrwashdeh@inu.edu.jo (M. Alrwashdeh)

(c) 2022 Growing Science Ltd. All rights reserved.

doi: $10.5267 /$ j.uscm.2021.12.012 
helps build institutional knowledge and enhance organizational efficiency by using analytical methods to make high-value decisions. Also, reduce operating costs, and accurately forecast market trends (Coombes \& Nicholson, 2013; Liu et al., 2016). Due to the complexity of SCM processes, SCs use software to simplify and standardize operations, but there is an urgent need for careful implementation to achieve the requirements of these systems (Liu et al., 2013; Liu et al., 2020). due to the success of information technology investments are often unreliable, the biggest challenge is how to make use of the data collected (Devaraj et al., 2007; Liu et al., 2016). Therefore, the use of BA provides a convenient methodology for analyzing big data and information to make strategic decisions (Kortmann et al., 2014; Frankenberger \& Sauer, 2019).

Corporate decision makers struggle to make optimal use of the big data available in SCM software (Kim \& Min, 2015; Guo et al., 2020). Companies often do not use the information obtained to control their day-to-day business operations; They only collect data to put in their business data repositories for later use (Ferreira et al., 2013; Ehret et al., 2013). This calls for knowing how to ensure that BA is actually used to improve SC processes (Coombes \& Nicholson, 2013; Chen \& Chen, 2020). There should be an approach focused on processes not on functions or tasks. Processes are what connect functions (Chen et al., 2018; Bellos et al., 2017), therefore, re-engineering business processes in a way that ensures the integration of processes and functions is the core of the process orientation (Amit and Zot, 2016; Kochon, 2018). This approach helps reduce information acquisition costs, reduce computations, improve processing capabilities, and create an efficient environment for data storage and sharing (Chen \& Chen, 2020; Chadwick et al., 2015). Decision making becomes ingrained in daily work, which is reflected in the maturity of BA.

Business Analysis (BA) is a SC tool and an integral part of an organization's business operations ( Cachon, 2018; Valente et al., 2007; Rialti et al., 2019). Correct business decisions depend on the analysis of large amounts of data obtained from inside and outside the organization, this is only possible by employing BA (Valente et al., 2007; Amit \& Zott, 2016). This has led to researchers' ever-increasing interest in BA and its impact on SCP (Kortmann et al., 2014). A study model was developed and tested to verify these relationships. This study may contribute to providing some recommendations that will help managers take the right decisions and improve the level of performance in SC.

Many industrial companies in KSA use their own databases and predictive models in the analysis processes to better guide the decision-making process (Adaileh \& Elrehail, 2018; Frankenberger \& Sauer, 2019). Thus, supply chain management helps in achieving competitive advantage and improving organizational performance. Companies that support the decisionmaking process by possessing enhanced analytical capabilities with the IS support and BPO in performing their tasks will be in a better competitive position (Teece, 2018; Salonen \& Jaakkola, 2015). Due to lack of understanding of the role of BA in SCP. Based on the above, we express the research statement through the following question: What is the role of employing BA in SCP and how can IS support and BPO mediate this impact.

Improving the efficiency and effectiveness of SC analysis is critical for increasing the SC's ability to achieve competitive advantage ( Sohl et al., 2020; Trkman et al., 2015; Rialti et al., 2019). This study uses a structured and organized method to clarify the areas of impact of BA on performance in Saudi industrial SCs.

\section{Literature review}

Based on Bose (2009) and Wixom et al, (2008) were defined BA as the use of several advanced analytic applications on data to help and solve problems related to SCM decisions. Within this approach, BA is not only a technology, but also organizational approaches and tools used together to obtain, analyze information, and predict solutions to problems in four areas of the SC operations (planning, source, make, and deliver).

Researchers believe that the adoption of SCM systems can improve financial performance by improving inventory turnover, reducing sales costs, and many additional benefits that can be achieved in the SC (Dehning et al., 2007; Liu et al., 2013; Lam et al., 2016; Ferreira et al., 2013; Munodawafa \& Johl, 2019; Pagoropoulos et al., 2017). Despite significant investments in SCM systems in the last few decades, these systems often struggle to achieve a competitive advantage (Chen et al., 2012; Gupta \& George, 2016; Mikalef et al., 2018; Rialti et al., 2012). The research focused on the initial experiences of BA rather than the evolution that occurs over time, raising a strong and urgent need to study the impact of BA, factors influencing this impact, and the SCM areas that have the greatest impact (Wixom et al., 2008). The process of linking and managing an organization's key resource (information) (i.e., the use of that information) is a key factor in organizational performance (Gupta \& George, 2016; Pagoropoulos et al., 2017). SCM practices emphasize use of information to improve processes (Kim $\&$ Min, 2015), additionally effective SC practices can increase the ability to process Information, therefore, information processing and the prior knowledge development process are critical for SC efficiency (Hult et al., 2004; Mcdonald \& Eisenhardt, 2020).

\subsection{BA and SC Performance}

The task of monitoring and improving SCP is a complex task because it involves many managerial processes such as setting standards and objectives, planning, communication, monitoring, reporting and implementation of most activities (Cai et al., 2009; Liu et al., 2020; Visnjic et al., 2016). It may become impossible to take an approach based on conventional wisdom, 
or use benchmarking or take advantage of best practices in making today's SC decisions (Chen \& Chen, 2020). Therefore, data analysis became integral for decision-making process, The same applies to the managerial decision-making process, which depends on large amount of big data, both internal and external, and this will be available only in the case of BA, which helps in analyzing the data collected on a structured basis.

The use of BA helps in the formation of institutional knowledge by enhancing efficiency, particularly, analytical methods provide comprehensive knowledge in decision-making (Hedgebeth, 2008; Adaileh \& AbuAlZeat, 2017; Amit \& Zott, 2016). Maturity in SC practices and high capabilities in BA can help organizations to reduce their costs and achieve a higher profit margin faster than competitors (Hall, 2005; Kim \& Min, 2015; Frankenberger \& Sauer, 2019). Advanced levels of SCM practices such as increased levels of information sharing and quality can lead to improve performance and (Pati et al., 2018). Oftentimes, many organizations that have systems for collecting data and information find themselves unable to make strategic decisions because they do not have a clear methodology for developing and using big data and information to make those decisions (Ranjan, 2008; Loon \& Chik, 2019; Munodawafa \& Johl, 2019). Organizations are constantly evaluate their current models to provide comprehensive and in-depth knowledge in complete conditions that affect performance ( Mikalef et al., 2018; Rialti et al., 2019.

\subsection{How does BA affect SC performance?}

In previous research, SCM concept is used as an umbrella for analyzing the impact of BA on performance (Chen et al., 2012; Gupta \& George, 2016; Gupta et al., 2019). SCM practices integrate organizational units and business processes along the SC and coordinate information, materials to meet customer requirements (Loon \& Chik, 2019; Liu et al., 2020). Therefore, this concept is still eclectic (Burgess et al., 2006; Sohl et al., 2020; Teece, 2018) and includes business activities in a company. Thus, it is necessary to indicate how business analysis affects more precisely. The four basic processes in SC model (planning, sourcing, making, and delivery) are used as a systematic approach to identifying, assessing and monitoring SC performance (Cai et al., 2009; Sohl et al., 2020; Zhu et al., 2018; Mcdonald \& Eisenhardt, 2020).

BA can be used in planning in SC through analyzing data and predicting market, products and service trends (Kortmann et al., 2014; Guo et al., 2020; Duanmu \& Pittman, 2018). In sourcing, the agent-based purchasing system is used with the agent purchasing to improve the supplier selection process, price negotiation and supplier evaluation. It is a method of selecting and evaluating suppliers. In manufacturing, the correct production of each component is related not only to time, but to volume and quantities. Finally, in delivery and logistics management, BA is used to bring products to market more efficiently (Reyes, 2005; Guo et al., 2020). It can be concluded that improvement in any of the four areas leads to an improvement in the SC performance. However, this positive impact of BA is not guaranteed, and mediator variables are needed through the support of information systems and also through the direction of BPO.

The link between IT use and business processes is vital, in practice it is often hard to separate the benefit achieved, whether it is the result of the use of IT or a change in the process, or both (Frankenberger \& Sauer, 2019; Amit \& Zott, 2016; Anwar, 2018). Internet technology has facilitated the improvement of business processes across the enterprises and other members of SC (Auramo et al., 2005; Pagoropoulos et al., 2017). Although the influence of these two variables is clear, the effect of each of these mediating variables still needs to be determined separately, and therefore, the impact of each mediating variable is discussed separately in the following sections.

\subsection{The mediating impact of $B P O$}

Business process reengineering projects improve business processes, increase BPO and improve performance (Zhu et al., 2018; Spieth et al., 2019). Decision makers in companies are struggling to make optimal use of the vast amounts of data available in SCM systems. Companies do not use the information they obtain to manage day-to-day business operations, but simply collect it to put into their business data repositories for later use (Shang et al., 2008; Salonen \& Jaakkola, 2015; Ehret et al., 2013). Actually, the question of how to ensure that BA is used to improve the functioning of the SC is becoming evident. This study also assumes that BPO mediates the impact of BA on SC performance. Therefore, both BA and BPO must be more mature to lead to better performance (Pagoropoulos et al., 2017; Rialti et al., 2019). Therefore, BA and BPO link functions, leaving functional direction to focus on the strategic and tactical levels (Gupta et al., 2019). Carefully analyzing for key business processes will integrate, manage business processes, which are considered best practices in supply chain management, and this also includes making coordination decisions across multiple facilities and levels (Meixell et al., 2005; Munodawafa \& Johl, 2019; Spieth et al., 2019). This call also for re-engineering business and embed business processes between organizations to take advantage of the benefits offered by strategic SC planning.

Business processes require a design that increases information processing capabilities and reduces the costs of obtaining and transmitting information (Visnjic et al., 2016). The use of BA creates a suitable environment for efficient storage and data sharing and creates different areas for processing (Trkman et al., 2015; Teece, 2018; Davenport, 2006). Organizations may need to undertake difficult and painful organizational change in order to increase information processing capabilities, implement change management practices and change decisions about internal SC activities and business operations (Watson et al., 2006). 
When an organization realizes these capabilities, it can use the data to improve operations. Leading and directing change in organizational culture to embed this in daily work, business analysis becomes more mature (Spieth et al., 2019; Sohl et al., 2020; Salonen \& Jaakkola, 2015; Rai \& Tang, 2014; Pati et al., 2018). A comprehensive BPO approach to the internal and external integration of business processes is one of the prerequisites for using BA (Popovic. et al, 2009).

\subsection{The mediating impact of IS support}

Information systems collect, store, process and transmit information (Encyclopaedia Britannica, 2010; Chen et al., 2012; Gupta \& George, 2016; Gupta et al., 2019; Pagoropoulos et al., 2017). BA depends on huge databases and information about the company and its operations for more advanced analysis (Mikalef et al., 2018; Rialti et al., 2019). The study assumes that BA impacts SC performance (Benaroch et al., 2007; Rialti et al., 2019), according to Mikalef et al., (2018), supporting information systems increases the company's ability to process, absorb complex external information, and increase effective response. Also, information systems affect the dynamic capabilities of the organization. Therefore, investment in information systems affects the performance of the SC by supporting core capabilities (Gupta et al., 2019; ( Mikalef et al., 2018; Rialti et al., 2019).

Researchers can propose direct and indirect impact (BPO and ISS as mediating variables) through the following seven hypotheses.

\section{$\mathbf{H}_{1}$ : BA positively impacts $B P O$.}

$\mathbf{H}_{2}$ : BA positively impacts ISS.

$\mathbf{H}_{3}$ : BA positively impacts $S C$ performance.

H4: BPO positively impacts SC performance.

\section{H5: IS support positively impacts SC performance.}

$\mathbf{H}_{6}$ : BPO positively mediates the impact of BA on SC performance.

$\mathbf{H}_{7}$ : IS support positively mediates the impact of BA on SC performance.

\section{Methods}

\subsection{Design}

The study used the descriptive and analytical approach, as this study aims to describe and organize information about the impact of BA, BPO and information systems support in SC performance. To achieve the study objectives, a questionnaire was developed for the purpose of collecting data. The survey included questions about key decision-making practices in the SC. Previous literature was reviewed, and interviews were conducted with academics, SC experts, and practitioners as an essential step in developing the questionnaire. The study extended to include many industries and many individuals who work in the field of SC.

Senior management positions in 38 companies in various industrial SCs were targeted. Jobs in sales and marketing, planning and scheduling, manufacturing, distribution and purchasing, engineering, and others in businesses related to the supply chain were selected. The researchers distributed 450 questionnaires and retrieved (395) with a percentage of (88\%) and a valid number for analysis (373), all of which were subjected to statistical analysis, and this percentage is a real representation of the study population, according to (Sakaran, 2010).

\section{Result}

\subsection{The Instrument}

According to Hair (2009), Fornell and Larcker (1981), a good measure is necessary to obtain appropriate results from hypothesis testing, which includes the structural relationships between variables. Hence, it is important to activate the structural components through the development of appropriate measurement indicators through which the survey instrument can be developed to collect data. So the study model was used in order to build the questionnaire. To achieve the objectives of the study, previous studies were scanned for developing the current study instrument. The scale developed consisting of the study variables that were mentioned in the study model and based on a group of studies (Hedgebeth, 2008; Hoole, 2005; Alrwashdeh et al., 2019; Meixell et al., 2005; Shang et al., 2008) to obtain the primary data necessary to complete the empirical part of the study. The instrument took into account the clarity of its objective, components, accuracy, consistency and unity of direction of movement of the scale in terms of form, type and method to serve the study objectives and hypotheses, multiple choice questions were used. The instrument has been reorganized to fit the research objectives (see appendix A). The questionnaire focused on the decision-making process of key SCM decisions for each area of SC operations that are planning, sourcing, making and delivery.

For the purposes of this research, some metrics that only represent BA practices within SC domains have been identified. SC performance depends on self-evaluation in the areas of the SC. This dimension is based on respondents' perceptions for each of the four SC areas. Respondents were asked whether or not they agreed with the questionnaire questions using a five-point 
Likert scale $(1=$ not at all applicable, $5=$ very applicable). Overall BPO is measured using a scale developed in previous research, according to the ISS support, it depends on self-evaluation. The question was directly asked whether IS supports the overall processes in the SC, order fulfilment process, distribution management, manufacturing process, resource related processes, and demand management. Since the value of technology depends on the tasks performed by the user, and user assessment can accurately reflect differences in the systems used and the services they provide, many survey respondents are technology users in their work.

A scale face validity requires consulting faculty members specializing in business, production management, as well as a group of experts in the field of SCs and practitioners. expertise. Some paragraphs were merged, deleted, and modified, which made the scale more accurate and subjective in measurement. Confirmatory factor analysis CFA was used in order to ascertain the validity and reliability of the Measurement Model, where the Convergent Validity and Discriminant Validity were confirmed for each Construct variable (Fornell \& Larcker, 1981; Hair, 2009). The goodness of fit indices (Hair, 2009) has been confirmed $(\chi 2 / \mathrm{df}=1.321(\mathrm{P}=0.023)$; $\mathrm{GFI}=.896 ; \mathrm{CFI}=.96 ; \mathrm{AGFI}=.852 ; \mathrm{RMSEA}=.052)$.

Table 1 shows Cronbach's alpha coefficient, composite reliability, and average variance extracted AVE. The internal consistency refers to the strength of the correlation of the elements in the construct in measuring, it was found that all values of Cronbach's alpha coefficient exceeded 0.70. Composite reliability refers to the stability and internal consistency between latent constructs (Hair et al. 2010). The composite reliability values exceeded 0.70 indicates the consistency of the measurement model. Finally, the AVE was calculated to indicate the variance explained by the questionnaire paragraphs, according to Hair et al. (2010) The AVE values must exceed 0.50 for all variables to indicate the reliability of the scale and the convergence (Hair et al., 2009; Alrwashdeh et al., 2020; Alshanty et al., 2019).

Table 1

Results of the confirmatory factor analysis

\begin{tabular}{lccc}
\hline Construct & Composite reliability & AVE & Cronbach Alpha \\
\hline Business analytics & 0.77 & 0.517 & 0.787 \\
Business process orientation & 0.758 & 0.513 & 0.86 \\
Information systems support & 0.716 & 0.566 & 0.778 \\
Supply chain performance & 0.798 & 0.512 & 0.782 \\
\hline
\end{tabular}

Note: $\mathrm{SE}=$ Standard Error, $\mathrm{CR}=$ Critical Ratio, $\mathrm{AVE}=$ Average Variance Extracted

Discriminant validity was verified by examining the correlation matrix for all the variables in the measurement model as well as the square root (SQRT) for AVE. According to Chin (1998), the SQRT (AVE) should exceed the correlation coefficients between the construct of the measurement model. Table 2 shows that SQRT (AVE) exceeded the correlation coefficients for all constructs, which indicates that they differ, and there is sufficient discriminant validity.

Table 2

Discriminant validity indicators (correlation coefficients, and SQRT (AVE)

\begin{tabular}{cccc}
\hline & BA & BPO & IS Support \\
\hline BA & 0.719 & & \\
BPO & 0.433 & 0.716 & 0.752 \\
IS Support & 0.409 & 0.233 & 0.326 \\
SCP & 0.344 & 0.427 & 0.715 \\
\hline
\end{tabular}

\subsection{Testing hypothesis}

Structural Equation Modeling SEM using AMOS.22 was used to estimate the direct and indirect relationships in the structural model. Indicators of fitness were found as follows: $\chi 2 / \mathrm{df}=1.562(0.000), \mathrm{GFI}=0.877, \mathrm{CFI}=0.901, \mathrm{AGFI}=0.825, \mathrm{RMSEA}=$ 0.068. Fig. 1 shows the structural model and estimation values for the relationships between constructs. Table 4 shows the test results for the direct paths analysis, where it was found that the impact of the BA on BPO is statistically significant and the value of standardized estimate is $0.691(\mathrm{H} 1=$ Accepted). The standardized estimate for the impact of the BA on IS support is 0.69 with a level of significance $0.000(\mathrm{H} 2=$ Accepted $)$, while the other tracks were not statistically significant, which indicates that there is no direct effect of those paths $(\mathrm{H} 3, \mathrm{H} 4, \mathrm{H} 5=$ Rejected).

\section{Table 4}

Structural Model Test, Standardized Regression Weights

\begin{tabular}{llllll}
\hline Hypothesis & Estimate & S.E. & C.R. (t-value) & P-Value & Decision \\
\hline $\mathrm{BA} \rightarrow$ BPO & 0.691 & 0.151 & 4.58 & $* * *$ & Accept \\
$\mathrm{BA} \rightarrow$ IS Support & 0.69 & 0.134 & 5.15 & 0.685 & Accept \\
$\mathrm{BA} \rightarrow$ SCP & 0.06 & 0.114 & 0.53 & 0.053 & Reject \\
$\mathrm{BPO} \rightarrow$ SCP & 0.201 & 0.096 & 2.09 & 0.277 & Reject \\
IS Support $\rightarrow$ SCP & 0.349 & 0.089 & 3.92 & Reject \\
\hline
\end{tabular}

S.E: Standard Error, C.R: Critical Ratio (t-value), P: Probability, *** Significant ant $P \leq 0.01$ 
For testing the mediating impact of IS support and BPO, according to Baron and Kenny. (1986), there are three cases in which the variable can be considered a mediator and carries the effect of the independent variable to the dependent variable. The mediation effect occurs when the independent variable significantly affects the mediating variable, and when the independent variable significantly affects the dependent variable in the absence of the mediator, and finally when the effect of the independent variable on the dependent variable changes when the mediator is added to the model. From Table 4, we note that there is no effect of the independent variable (BA) on the SC performance, where the value of standardized estimate is 0.06 and is not statistically significant.

But there is a significant impact of the BA on both BPO and IS support (standardized estimates $=0.691,0.69$ ). The total impact of BA on SC performance with the mediation of BPO Using the Sobel Test (0.138) which is higher than the direct effect of the independent variable on the dependent (0.06), it can be said that the BPO mediates the effect of the BA on SC performance (H6= Accepted). The overall effect of the BA on SC performance with the mediation IS Support using the Sobel Test was (0.241), which is higher than the direct effect of the independent variable on the dependent (0.06), and it can also be said that IS support mediate the effect of the BA on SC performance (H7= Accepted).

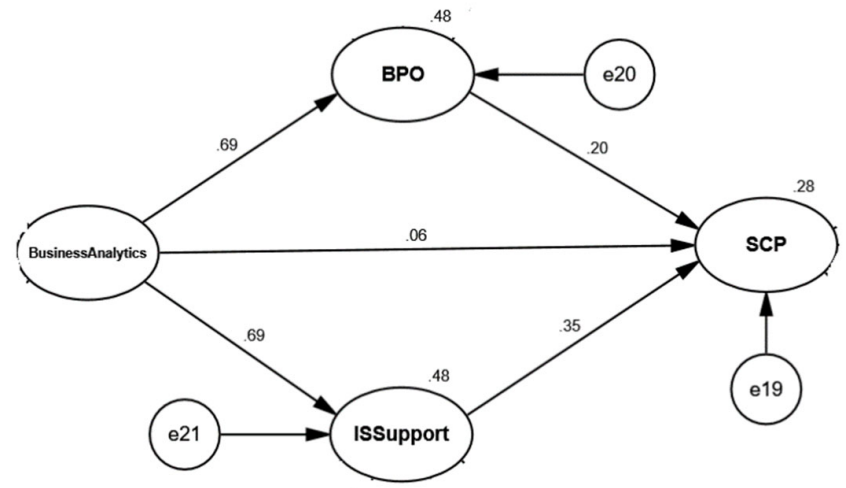

Fig. 1. Model Outputs: Relationship's coefficients and direct and indirect effects of the study dimensions (standard errors)

\section{Discussion}

Decision making depends on the analysis of huge external and internal data in order to make decisions. Therefore, most systems struggle to gain competitive advantage due to the difficulty of providing reliable methods for measuring business value. According to (Hult et al., 2004; Henderson et al., 1992; Cadez et al., 2008; Azvine et al., 2005; Sahay et al., 2008), the process of developing knowledge, exploiting information to improve processes and outputs is an important precedent for increasing the SC efficiency and the focus of activities in supply management. This can only be achieved by using BA capabilities to analyze huge data on a structured basis.

Results indicated a direct significant impact of BA on BPO, many researchers (e.g., Groznik et al., 2008; Greasley, 2006; Mikalef et al., 2019; Mikalef et al., 2018; Rialti et al., 2019) indicated that projects to redesign BA capabilities enhance business processes and improve efficiency and business performance. Companies that have a more process orientation are in a better position to benefit from BA in order to improve performance (Popovic et al., 2009; Ringle et al., 2007; Chen et al., 2012; Gupta \& George, 2016; Gupta et al., 2019; Pagoropoulos et al., 2017). BA systems must have a process orientation in order to link jobs and leave the functional orientation that focuses on the strategic and tactical levels.

There is a need to redesign the business and include the inter-organizational business processes to take advantage of the advantages provided by strategic planning for the supply chain, as the study of Lambert et al., (2000) indicates that executives must carefully analyze the main business processes in order to integrate, manage and integrate business processes, it is considered one of the best practices in supply chain management, and this also includes making coordination decisions across multiple facilities and levels.

Reengineering inter-organizational embedded business helps to benefit from strategic planning in Sc. It integrates business processes and makes coordination decisions across specific facilities and multiple levels (Lambert et al., 2000; Pagoropoulos et al., 2017). Furthermore, the results indicated the impact of BA on IS support. Bose, (2009) indicated that BA is an approach and organizational procedures, not a technology, meaning that all BA tools and methods must be used with each other to obtain information, analyze, and predict the outputs of solutions to problems in SC operations. Also, the full use of information systems must be enhanced by the process orientation towards activities and operations, the application of change management practices, and decisions related to the SC's internal activities. BPO includes both the internal and external integration of business processes (Wixom et al., 2008; Cachon, 2018; Bellos et al., 2017; Anwar, 2018; Amit \& Zott, 2016). 
The results supported the assumption of the mediating effect of BPO between BA and SC performance. The result emphasizes the need for a process-oriented approach to linking functions. There is a need to embrace change management, make comprehensive changes in business processes to take advantage of BA capabilities (Auramo et al., 2005 \& Valente et al., 2007; Rialti et al., 2019; Chen \& Chen, 2020), change decision-making approaches to internal activities in the supply chain (Watson et al., 2006; Gupta et al., 2019). The positive impact of BA requires mediating factors such as IS support and BPO. However, this also requires a redesign of business processes. This proposed impact of supporting information systems is consistent with findings that investment in information systems affects performance through IS support for core capabilities, and may have an additional, independent effect on SC performance (Lam et al., 2016; Cortman et al., 2014; Kim \& Min, 2015; Guo et al., 2020).

Few studies have discussed the impact of BA, BPO IS support on SC performance. Dehning et al. (2007) indicated that organizations can improve the financial performance in inventory and reduce the cost of sales and many additional benefits through the adoption of supply chain systems, along with the link between organizational resources such as information and its management to improve organizational performance. Hult et al. (2004) indicate that effective practices in using information in SC can increase the capacity of information processing, and this is confirmed by several researchers such as. (Frankenberger \& Sauer, 2019; Ferreira et al., 2013; Ehret et al., 2013; Duanmu \& Pittman, 2018). Increasing levels of information sharing enhances performance improvement, Hedgebethm (2007) concluded that the use of supply chain systems enhances internal efficiency in the organization. Analytical methods are also used in order to make decisions of high value (such as market forecasting, recent trends in the markets, reducing operating costs, achieving a higher profit margin than peers).

Several researchers (e.g., Chen et al., 2012; Gupta et al., 2019; Pagoropoulos et al., 2017; Munodawafa \& Johl, 2019; Auramo et al., 2005), indicate that the positive impact of business BA needs mediating factors by supporting information systems and perhaps also by BPO operations. It indicated that business process redesign projects can lead to improving business processes and increasing orientation. BPO improves efficiency and improves business performance. McCormack, (2007), Dale Stoel et al. (2009) and Mikalef et al. (2019) indicated that information systems can increase the company's ability to process information. Companies that have information systems with superior capabilities are better able to collect, process and assimilate external and complex information and can formulate an effective response. They pointed out that information systems are important because they have an important impact on the dynamic capabilities of the organization. It can be considered that information systems play a mediating role in the impact of business analysis on the performance of the supply chain. This proposed effect of supporting information systems is in line with the results that say that investment in information systems affects performance by supporting information systems for basic capabilities.

Pagoropoulos et al. (2017), Munodawafa and Johl (2019) and Auramo et al. (2005) suggest that the positive impact of BA needs mediating IS support and possibly BPO. They noted that business process re-engineering projects can lead to improved business operations and increased orientation. BPO improves efficiency and improves business performance as indicated by several researchers (e.g., McCormack (2007), Dale Stoel et al. (2009) and Mikalef et al., 2019).

\section{Recommendations}

The researchers suggested some recommendations aimed at activating the use of BA, BPO, and IS support in improving the SC performance in Saudi industrial companies.

Companies in Saudi Arabia must develop the analytic capabilities for managers, raising awareness about the benefits that can be reaped from using the BA approach as it is an important precedent for SC efficiency. Moreover, recognizing the importance of BPO in the performance of activities, focusing on the importance of information systems, and employing these dimensions to achieve desired goals such as performance. This process should be carried out by managers who have gained diverse experiences and reached a high degree of maturity due to repetitive practices of SCM. This process involves re-engineering the processes and making continuous improvements from time to time whenever the need arises because it becomes necessary as the value-added decreases.

Companies must support their analytical capabilities with good IS in analyzing huge amounts of internal and external data, by increasing knowledge and employing cognitive capabilities through training. Additionally, investing and using existing analytical capabilities as an approach to the decision-making process. Training must be conducted by knowledge management experts in order to take full advantage of the experiences and practices in the SC. The training process should also be supervised by experts in information systems in order to develop data processing and storage capabilities. The training plan should be along working periods to ensure continuous improvement in capabilities. This study suggests further future studies, which should include a case study to get a more comprehensive view of how BA affects performance. Examine the different potential impacts of BA on companies at different levels of outsourcing. Those future studies should extend to an in-depth investigation into the effect of BA and BPO in different areas of SCs performance such as flexibility, reliability, quality, costs, on-time delivery and competitive advantage. 


\section{References}

Adaileh, M., \& Abualzeat, H. (2017). Impact of knowledge sharing and leakage on innovative performance. Journal of Sustainable Development, 10(1), 92-111.

Adaileh, M. J., \& Elrehail, H. (2018). E-business supply chain collaboration measurement scale: a confirmatory approach. International Journal of Supply Chain Management, 7(5), 22-34.

Alshanty, A., Emeagwali, O., Ibrahim, B., \& Alrwashdeh, M. (2019). The effect of market-sensing capability on knowledge creation process and innovation Evidence from SMEs in Jordan. Management Science Letters, 9(5), 727-736.

Alrwashdeh, M., Jahmani, A., Ibrahim, B., \& Aljuhmani, H. Y. (2020). Data to model the effects of perceived telecommunication service quality and value on the degree of user satisfaction and e-WOM among telecommunications users in North Cyprus. Data in brief, 28, 104981.

Alrwashdeh, M., Emeagwali, O., \& Aljuhmani, H. (2019). The effect of electronic word of mouth communication on purchase intention and brand image: An applicant smartphone brands in North Cyprus. Management Science Letters, 9(4), 505-518.

Alshammari, A.F., \& Adaileh, M.J. (2018). E-Learning Readiness: A Scale Development in Saudi Higher Education Institutions. International Journal of Economic Management Science, 7, 553. doi: 10.4172/2162-6359.1000553

Amit, R., \& Zott, C. (2016). Business model design: A dynamic capability perspective. In D. J. Teece, \& S. Leih (Eds.), The Oxford handbook of dynamic capabilities (pp. 1-21). Oxford: OUP.

Anwar, M. (2018). Business model innovation and SMEs performance: Does competitive advantage mediate? International Journal of Innovation Management, 22(7), 1850057.

Auramo, J., Kauremaa, J., \& Tanskanen, K. (2005); Benefits of IT in supply chain management: an explorative study of progressive companies. International Journal of Physical Distribution \& Logistics Management, 35(2).

Bellos, I., Ferguson, M., \& Toktay, L. B. (2017). The car sharing economy: Interaction of business model choice and product line design. Manufacturing \& Service Operations Management, 19(2), 185-201.

Benaroch, M., Jeffery, M., Kauffman, R., \& Shah, S. (2007). Option-based risk management: field study of sequential IT investment decisions. Journal of Management Information Systems, 24(2).

Bose. R. (2009). Advanced analytics: opportunities and challenges. Industrial Management \& Data Systems, 109(2).

Burgess, K., Singh, P., \& Koroglu, R. (2006). Supply chain management: a structured literature review and implications for future research. International Journal of Operations \& Production Management, 26(7).

Cachon, G. P. (2018). A research framework for business models: What is common among fast fashion, e-tailing, and ride sharing. Management Science, 66(3), 1005-1507.

Cai, J., Liu, X., Xiao, Z., \& Liu, J. (2009). Improving supply chain performance management: a systematic approach to analyzing iterative KPI accomplishment. Decision Support Systems, 46(2).

Chadwick, C., Super, J. F., \& Kwon, K. (2015). Resource orchestration in practice: CEO emphasis on SHRM, commitmentbased HR systems, and firm performance. Strategic Management Journal, 36(3), 360-376.

Chen, H., Chiang, R.H.L., Storey, V.C. (2012). Business Intelligence and Analytics: From Big Data to Big Impact. MIS Quarterly, 36(4), 1165-1188.

Chen, M., Liu, H. F., Wei, S. B., \& Gu, J. B. (2018). Top managers' managerial ties, supply chain integration, and firm performance in China: A social capital perspective. Industrial Marketing Management, 74, 205-214.

Chen, Y., Liu, H., \& Chen, M. (2020). Achieving novelty and efficiency in business model design: Striking a balance between IT exploration and exploitation. Information \& Management, 103268.

Coombes, P. H., \& Nicholson, J. D. (2013). Business models and their relationship with marketing: A systematic literature review. Industrial Marketing Management, 42(5), 656-664.

Dale Stoel, M., \& Muhanna, W.A. (2009). IT capabilities and firm performance: a contingency analysis of the role of industry and IT capability type. Information \& Management, 46(3).

Davenport, T. (2006). Competing on analytics. Harvard Business Review 84(5).

Dehning, B., Richardson, V.J., \& Zmud, R.W. (2007). The financial performance effects of ITbased supply chain management systems in manufacturing firms. Journal of Operations Management, 25(4).

Devaraj, S., Krajewski, L., \& Wei, J. (2007). Impact of e-business technologies on operational performance: The role of production information integration in the supply chain. Journal of Operations Management, 25(6), 1199-1216.

Duanmu, J. L., Bu, M. L., \& Pittman, R. (2018). Does market competition dampen environmental performance? Evidence from China. Strategic Management Journal, 39(11), 3006-3030.

Ehret, M., Kashyap, V., \& Wirtz, J. (2013). Business models: Impact on business markets and opportunities for marketing research. Industrial Marketing Management, 42(5), 649-655.

Ferreira, F. N. H., Proença, J. F., Spencer, R., \& Cova, B. (2013). The transition from products to solutions: External business model fit and dynamics. Industrial Marketing Management, 42(7), 1093-1101.

Fornell, C., \& Larcker, D. F. (1981). Evaluating structural equation models with unobservable variables and measurement error. Journal of Marketing Research, 18(1),39-50.

Frankenberger, K., \& Sauer, R. (2019). Cognitive antecedents of business models: Exploring the link between attention and business model design over time. Long Range Planning, 52(3), 283-304.

Guo, H, Wang, C., Su, Z., \& Wang, D. (2020). Technology push or market pull? Strategic orientation in business model design and digital startup performance. Journal of Product Innovation Management, 37(4), 352-372. 
Gupta, M., \& George, J.F. (2016). Toward the development of a big data analytics capability. Information Management, 53, 1049-1064. https://doi.org/10.1016/j.im.2016.07.004.

Gupta, S., Chen, H., Hazen, B. T., Kaur, S., \& Gonzalez, E. D. S. (2019). Circular economy and big data analytics: A stakeholder perspective. Technological Forecasting and Social Change, 144, 466-474.

Hedgebeth, D. (2007). Data-driven decision making for the enterprise: an overview of business intelligence applications. VINE, 37(4).

Hoole, R. (2005); Five ways to simplify your supply chain. Supply Chain Management: An International Journal, 10(1).

Hult, G.T.M., Ketchen, D.J., \& Slater, S.F. (2004). Information processing, knowledge development and strategic supply chain performance. Academy of Management Journal, 47(2).

Kim, S. K., \& Min, S. (2015). Business model innovation performance: When does adding a new business model benefit an incumbent? Strategic Entrepreneurship Journal, 9(1), 34-57.

Kortmann, S., Gelhard, C., Zimmermann, C., \& Piller, F. T. (2014). Linking strategic flexibility and operational efficiency: The mediating role of ambidextrous operational capabilities. Journal of Operations Management, 32(7-8), 475-490.

Lam, H. K., Yeung, A. C., \& Cheng, T. E. (2016). The impact of firms' social media initiatives on operational efficiency and innovativeness. Journal of Operations Management, 47, 28-43.

Liu, C., Feng, Y., Lin, D., Wu, L., \& Guo, M. (2020). Iot based laundry services: An application of big data analytics, intelligent logistics management, and machine learning techniques. International Journal of Production Research, 58(17), 5113-5131.

Liu, H., Ke, W., Wei, K. K., \& Hua, Z. (2013). Effects of supply chain integration and market orientation on firm performance. International Journal of Operations \& Production Management, 33(3), 322-346.

Liu, H., Wei, S., Ke, W., Wei, K. K., \& Hua, Z. (2016). The configuration between supply chain integration and information technology competency: A resource orchestration perspective. Journal of Operations Management, 44, 13-29.

Loon, M., \& Chik, R. (2019). Efficiency-centered, innovation-enabling business models of high tech SMEs: Evidence from Hong Kong. Asia Pacific Journal of Management, 36 (1), 87-111.

McCormack, K. (2007). Business Process Maturity: Theory and Application. BookSurge Publishing, Charleston, South Carolina.

Mcdonald, R., \& Eisenhardt, K. M. (2020). Parallel play: Startups, nascent markets, and effective business model design. Administrative Science Quarterly, 65(2), 483-523.

Meixell, M.J., \& Gargeya, V.B. (2005). Global supply chain design: a literature review and critique. Transportation Research Part E: Logistics and Transportation Review, 41 (6).

Mikalef, P., Krogstie, J., Pappas, I. O., \& Pavlou, P. (2020). Exploring the relationship between big data analytics capability and competitive performance: The mediating roles of dynamic and operational capabilities. Information \& Management, 57(2), 103169.

Mikalef, P., Pappas, I. O., Krogstie, J., \& Giannakos, M. (2018). Big data analytics capabilities: a systematic literature review and research agenda. Information Systems and e-Business Management, 16(3), 547-578.

Munodawafa, R.T., \& Johl, S.K. (2019). Big data analytics capabilities and eco-innovation: a study of energy companies. Sustainability, 11, 4254.

Pagoropoulos, A., Pigosso, D.C.A., \& McAloone, T.C. (2017). The emergent role of digital technologies in the circular economy: a review. Procedia CIRP, 64, 19-24.

Pati, R. K., Nandakumar, M. K., Ghobadian, A., Ireland, R. D., \& O’Regan, N. (2018). Business model design-performance relationship under external and internal contingencies: Evidence from SMEs in an emerging economy. Long Range Planning, 51, 750-769.

Popovic, A., Coelho, P.S., \& Jaklic, J. (2009). The impact of business intelligence system maturity on information quality. Information Research, 14(4).

Rai, A., \& Tang, X. (2014). Research commentary-Information technology-enabled business models: A conceptual framework and a coevolution perspective for future research. Information Systems Research, 25(1), 1-14.

Ranjan, J. (2008). Business justification with business intelligence, VINE: The journal of information and knowledge management systems, 38(4).

Reyes, P.M. (2005); Logistics networks: a game theory application for solving the transshipment problem. Applied Mathematics and Computation, 168(2).

Rialti, R., Marzi, G., Ciappei, C., \& Busso, D. (2019). Big data and dynamic capabilities: a bibliometric analysis and systematic literature review. Management Decision, 57(8), 2052-2068.

Salonen, A., \& Jaakkola, E. (2015). Firm boundary decisions in solution business: Examining internal vs. external resource integration. Industrial Marketing Management, 51, 171-183.

Shang, J., Tadikamalla, P.R., Kirsch, L.J., \& Brown, L. (2008). A decision support system for managing inventory at GlaxoSmithKline. Decision Support Systems, 46(1).

Sohl, T., Vroom, G., \& McCann, B. T. (2020). Business model diversification and firm performance: A demand-side perspective. Strategic Entrepreneurship Journal, 14(2), 198-223.

Spieth, P., Schneider, S., Clauß, T., \& Eichenberg, D. (2019). Value drivers of social businesses: A business model perspective. Long Range Planning, 52(3), 427-444.

Stadtler, H. (2005). Supply chain management and advanced planning basics, overview and challenges. European Journal of Operational Research, 163(3). 
Su, J., Zhang, S., \& Ma, H. (2020). Entrepreneurial orientation, environmental characteristics, and business model innovation: a configurational approach. Innovation, 22(4), 399-421.

Teece, D. J. (2018). Business models and dynamic capabilities. Long Range Planning, 51(1), 40-49.

Trkman, P., Budler, M., \& Groznik, A. (2015). A business model approach to supply chain management. Supply Chain Management, 20(6), 587-602.

Trkman, P., Indihar Štemberger, M., Jaklic, J., Groznik, A. (2007). Process approach to supply chain integration. Supply Chain Management - An International Journal, 12(2).

Valente, P., \& Mitra, G. (2007). The evolution of web-based optimization: from ASP to e- Services. Decision Support Systems, 43(4).

Visnjic, I., Wiengarten, F., \& Neely, A. (2016). Only the brave: Product innovation, service business model innovation, and their impact on performance. Journal of Product Innovation Management, 33(1), 36-52.

Watson, H.J., Wixom, B.H., Hoffer, J.A., Anderson-Lehman, R., \& Reynolds, A.M. (2006). Realtime business intelligence: best practices at continental airlines. Information Systems Management, 23(1).

Wei, Z., Song, X., \& Wang, D. (2017). Manufacturing flexibility, business model design, and firm performance. International Journal of Production Economics, 193, 87-97.

Wieland, H., Hartmann, N. N., \& Vargo, S. L. (2017). Business models as service strategy. Journal of the Academy of Marketing Science, 45(6), 925-943.

Wixom, B.H., Watson, H.J., Reynolds, A.M., \& Hoffer, J.A. (2008). Continental Airlines Continues to Soar with Business Intelligence. Information Systems Management, 25(2).

Zhu, Q., Krikke, H., \& Caniels, M. C. (2018). Supply chain integration: Value creation through managing inter-organizational learning. International Journal of Operations \& Production Management, 38(1), 211-229.

\section{Appendix A}

The survey Questionnaire

\begin{tabular}{|c|c|}
\hline \multicolumn{2}{|c|}{ Business analytical capabilities } \\
\hline BA1 & Adequate analysis tools are used for strategic planning, performance measures and measuring forecasting accuracy. \\
\hline BA2 & Collaboration and sharing of planning and scheduling information with suppliers is documented \\
\hline BA3 & Planning operations are coordinated and integrated across departments in the company, including sales, manufacturing, \\
\hline BA4 & The company uses mathematical and analytical tools to aid distribution planning \\
\hline \multicolumn{2}{|c|}{ Business process orientation } \\
\hline BPO1 & The company's supply chain operations are well known and documented \\
\hline BPO2 & The supply chain organizational structure is entirely process-oriented rather than focused on traditional functions \\
\hline BPO3 & Total supply chain performance measures focus more on process than on traditional functions \\
\hline BPO4 & Supply chain organization generally focuses more on customers than on people within the supply chain \\
\hline BPO5 & Functions in the supply chain are generally viewed as broadly process-oriented rather than narrowly focused \\
\hline \multicolumn{2}{|r|}{ 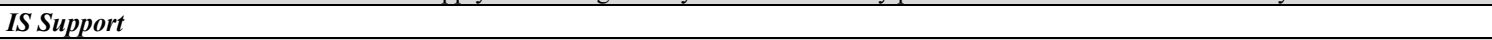 } \\
\hline ISS1 & The company's information system currently supports supply chain processes \\
\hline ISS2 & The company's information system is currently supporting the order fulfillment process \\
\hline ISS3 & The company's information system supports distribution management \\
\hline ISS4 & The company's information system is currently supporting the Make/ manufacturing process \\
\hline ISS5 & The company's information system is currently supporting the sourcing process \\
\hline ISS6 & The company's information system is currently supporting the order management process \\
\hline \multicolumn{2}{|c|}{ Supply Chain performance } \\
\hline SCP1 & Plan operations areas are implemented appropriately \\
\hline SCP2 & Sourcing operations areas are executed appropriately \\
\hline SCP3 & Make operations are executed properly \\
\hline SCP4 & Delivery operations are implemented appropriately \\
\hline
\end{tabular}

